\title{
Microstructure-Tensile Properties Relationship and Austenite Stability of a Nb-Mo Micro-Alloyed Medium-Mn TRIP Steel
}

\author{
Chunquan Liu ${ }^{1}$, Qichun Peng ${ }^{1, *(\mathbb{D})}$, Zhengliang Xue ${ }^{1}$, Mingming Deng ${ }^{1}$, Shijie Wang ${ }^{1}$ and \\ Chengwei Yang ${ }^{2}$ \\ 1 The State Key Laboratory of Refractories and Metallurgy, Key Laboratory for Ferrous Metallurgy and \\ Resources Utilization of Ministry of Education, Wuhan University of Science and Technology, \\ Wuhan 430081, China; liuchunquan@wust.edu.cn (C.L.); xuezhengliang@wust.edu.cn (Z.X.); \\ dengmingming1993@163.com (M.D.); wangshijie1994@163.com (S.W.) \\ 2 Wuhan Bao Steel Central Research Institute, Wuhan 430083, China; ycw258@baosteel.com \\ * Correspondence: pengqichun1964@163.com; Tel.: +86-027-8687-0323
}

Received: 25 June 2018; Accepted: 2 August 2018; Published: 6 August 2018

\begin{abstract}
This study investigated the microstructure-tensile properties relationship and the retained austenite room temperature stability of a $\mathrm{Nb}$ and Mo micro-alloyed medium manganese transformation induced plasticity (TRIP) steel. A number of findings were obtained. Most importantly, the steel after being processed by quenching and tempering ( $Q$ \& $T$ ) exhibited excellent tensile properties, i.e., the strength of $878-1373 \mathrm{MPa}$, the ductility of $18-40 \% \mathrm{Mo}$, and $\mathrm{Nb}$ microalloying served to control the fraction of retained austenite and to improve tensile strength by fine grain strengthening. Excellent tensile properties were attributable to the large amount of retained austenite which produced a discontinuous TRIP effect. This effect led to the production a large amount of martensite which relieved the stress concentration, contributing to the coordinated deformation between the phases and thus improving the deformability of the steel. Additionally, the differences in $\mathrm{Mn}$ and $\mathrm{C}$ contents led to varying degrees of austenite stability and the length of the Lüders band decreased as the intercritical annealing temperature increased. The micro-alloyed medium manganese steel experimented on our study showed considerable improvement in tensile properties in comparison with the $5 \mathrm{Mn}-0.1 \mathrm{C}$ medium manganese steel in previous studies.
\end{abstract}

Keywords: medium Mn steel; (Nb; Mo)micro-alloyed; tensile properties; TRIP effect; austenite stability

\section{Introduction}

Research on automobile plate steel has focused on improving fuel economy and reducing exhaust emissions by lessening vehicle weight in recent years [1]. One plausible strategy to do so is to replace steel with lightweight material such as aluminum alloy, magnesium alloy, composite materials, and carbon fiber [2]. However, those materials are far from ready to substitute steel yet due to numerous problems, including unsatisfactory formation properties, inferior strength and weld ability and, in the case of carbon fiber, the prohibitive cost. As a result, research attention has been shifted to a kind of advanced high-strength steel (AHSS), medium-Mn (4-11\%) steel.

As a candidate for automobile plate, medium-Mn steel has such attractive properties as excellent combination of high strength and considerably large ductility ( $>30 \mathrm{GPa} \%$ ), light weight, high safety, and relatively lower alloying cost [3-9]. These properties result from the addition of a number of elements featuring Mn. Mn, an austenite stabilizer, triggers an extensive TRIP effect by enhancing the austenite volume fraction, which in turn increases steel strength and ductility. Meanwhile, other 
elements may be added to medium-Mn steel to further improve its properties. Among them are Al and $\mathrm{C}$. The addition of 1-3 wt.\% Al enhances the kinetics of martensite transformation and promotes precipitation hardening in the martensite matrix [3]. The addition of a trace amount of $C$ (up to $\sim 0.2 \mathrm{wt} . \%$ ) enhances the kinetics of austenite reversion and austenite stability, and the strength of the alloy [4].

However, these elements can also cause problems. For manganese, most studies added over 5\% of this metal to steel. For example, Li et al. [5] reported that hot-rolled $6.1 \mathrm{wt}$.\% Mn steels exhibited superior combination of ultimate tensile strength of $902-1235 \mathrm{MPa}$ and total elongation of $18-42 \%$. Zhao et al. [6] revealed that warm-rolled $7.9 \mathrm{wt} . \%$ Mn steels showed superior combination of ultimate tensile strength of $1600 \mathrm{MPa}$ and total elongation of 29\%. Cai et al. [7] found that cold-rolled11 wt.\% Mn steel had a tensile strength of $1007 \mathrm{MPa}$ and an overall elongation of $65 \%$. They all added over $5 \%$ of manganese because a larger amount of it can better increase austenite stability and stimulate the TRIP effect, thus improving the mechanical properties of the steel. However, high manganese content is prone to segregation, leading to the initiation of brittle cracks [8], and the effect of Mn addition is to decrease the rate of precipitation and the equilibrium precipitate fraction at a given temperature [9]. For this reason, some researchers tried to control manganese below 5\%. For example, Merwin [10] reported that cold-rolled $5 \mathrm{wt}$ \% Mn steels achieved a strength-ductility balance exceeding $30 \mathrm{GPa} \%$ after the austenite-reverted transformation (ART) heat treatment. Although they succeeded in avoiding the negative effects caused by high manganese content, the medium manganese steel they produced was relatively poor in performance.

A method which can improve steel performance while reducing negative effect is to add trace elements such as $\mathrm{Nb}$ and Mo to medium manganese steel. The addition of the microalloying $\mathrm{Nb}$ and Mo to medium Mn TRIP steel can increase steel strength because they are conducive for grain refinement, precipitation and solid solution hardening [11]. In addition, they reduce the tendency of $\mathrm{Mn}$ and $\mathrm{Al}$ to separate during casting and thermoforming [12], and stabilize austenite against transformation to martensite during cooling [13]. Cai et al. [14] experimented adding 0.22 wt.\% Mo and $0.05 \mathrm{wt} . \% \mathrm{Nb}$ to $6.5 \mathrm{wt} . \% \mathrm{Mn}$ medium Mn steel. The resulting steel exhibited slightly higher ductility and yield strength (YS) values. While their results were satisfactory in terms of ductility and yield strength, their approach could be expensive because of (1) the high prices of manganese, $\mathrm{Nb}$, and Mo, and (2) the complicated processes they adopted.

In this study, we hope to improve steel performance without significantly increasing costs. Accordingly, we investigated the relationship between microstructure and tensile properties of $\mathrm{Nb}-\mathrm{Mo}$ micro-alloyed $4.73 \mathrm{wt}$ \% Mn steel with an alloy content of no more than $6 \mathrm{wt}$.\% with a much simpler process. Most importantly, we aim to explore the microstructure evolution, mechanical properties, and retained austenite stability in micro-alloyed medium manganese steels. Meanwhile, we also hope to reveal the relationships between deformation behavior and austenite stability, between the effect of temperature on the formation and propagation of Lüders band, and between the discontinuous TRIP effect and the effect of niobium alloying on the microstructure and tensile properties of the experimental steel.

\section{Experimental Procedure}

The chemical composition of medium manganese steel was $0.12 \mathrm{C}-4.73 \mathrm{Mn}-0.82 \mathrm{Al}-0.19 \mathrm{Mo}-0.03 \mathrm{Nb}-\mathrm{Fe}$ (wt.\%). A $50 \mathrm{~kg}$ vacuum induction melting was used to prepare an experimental steel ingot which was then forged into rods of section size $50 \times 30 \mathrm{~mm}$. Afterwards, the ingot was homogenized at $1200{ }^{\circ} \mathrm{C}$ for $2 \mathrm{~h}$ and hot rolled to $3.6 \mathrm{~mm}$-thick plates via 5 passes between $1150{ }^{\circ} \mathrm{C}$ and $850{ }^{\circ} \mathrm{C}$, and subsequently water quenched (WQ) to room temperature (RT). Finally, the steel ingot was cold rolled to $2 \mathrm{~mm}$ sheets via 3 passes with the reduction of $44 \%$. The transformation temperatures $\left(\mathrm{A}_{C} 1\right.$ of $614{ }^{\circ} \mathrm{C}, \mathrm{A}_{\mathrm{C}} 3$ of $765^{\circ} \mathrm{C}$ ) were calculated using dilatometry. The sample used for dilatometry was a solid cylindrical specimen with a length of $10 \mathrm{~mm}$ and a diameter of $3 \mathrm{~mm}$. The dilatometric curve of the experimental steel is shown in Figure 1. The steel sample was heated and kept at a rate of $20^{\circ} \mathrm{C} / \mathrm{s}$ from room temperature 
to $900{ }^{\circ} \mathrm{C}$ for thermal expansion for $20 \mathrm{~min}$, and then cooled to the martensite start temperature (Ms) at $100{ }^{\circ} \mathrm{C} / \mathrm{s}$. Since long-term intercritical annealing would make austenite too stable to inhibit the TRIP effect [15], the Q\&T treatment method for cold rolled strip was adopted. During the Q\&T heat treatment process, the experimental steel samples were first annealed at $600{ }^{\circ} \mathrm{C}, 625{ }^{\circ} \mathrm{C}, 650{ }^{\circ} \mathrm{C}, 675{ }^{\circ} \mathrm{C}$, $700{ }^{\circ} \mathrm{C}$, and $750{ }^{\circ} \mathrm{C}$ for $30 \mathrm{~min}$ respectively, and next WQ to room temperature and then tempered at $200{ }^{\circ} \mathrm{C}$ for $15 \mathrm{~min}$ (as shown in Figure 2).

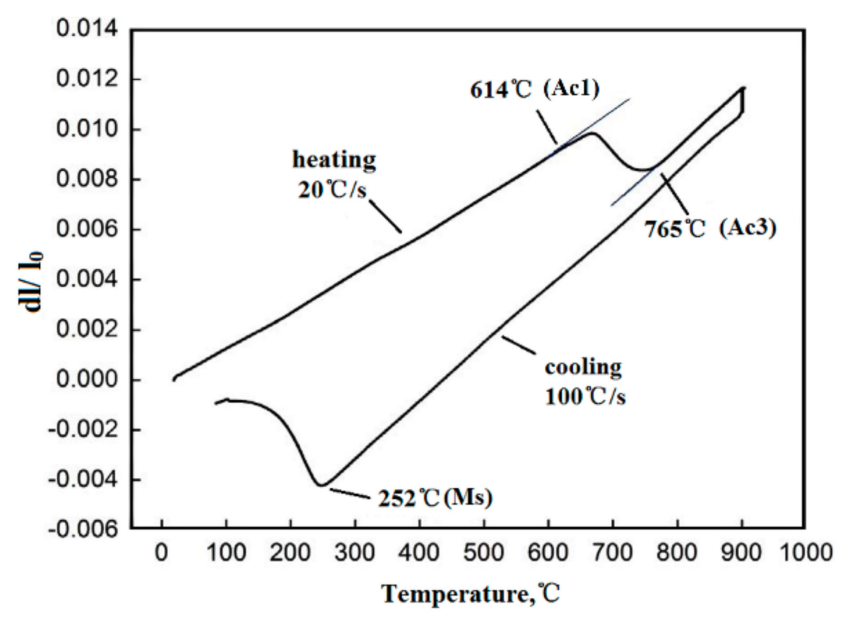

Figure 1. Dilatometric curves for the experimental steel.

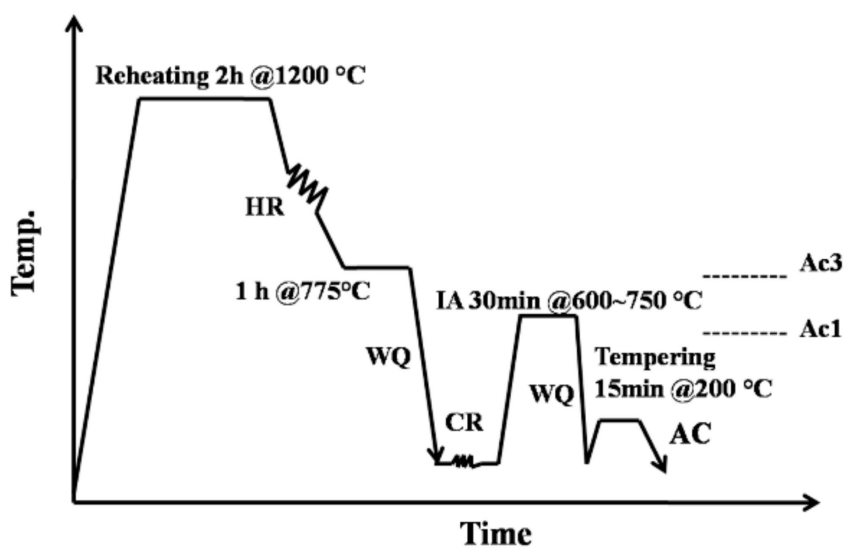

Figure 2. Schematic of the thermo-mechanical treatment for the experimental steel, intercritical annealing temperatures are $600{ }^{\circ} \mathrm{C}, 625{ }^{\circ} \mathrm{C}, 650{ }^{\circ} \mathrm{C}, 675{ }^{\circ} \mathrm{C}, 700{ }^{\circ} \mathrm{C}$, and $750{ }^{\circ} \mathrm{C}$ (HR: hot rolling, $\mathrm{CR}$ : cold rolling, AC: air cooling, WQ: water quenching, IA: intercritical annealing).

Tensile specimens were machined to a standard GB/T 228-2010 size of $12.5 \mathrm{~mm}$ width and $50 \mathrm{~mm}$ gauge length along the rolling direction. The room temperature tensile test was carried out with a constant $3 \mathrm{~mm} \cdot \mathrm{min}^{-1}$ cross head speed at the UTM5305 universal tensile test machine (Shenzhen, China). The retained austenite content of the sample was calculated by analyzing the XRD diffraction energy spectrum. The microstructure of the steel was observed by optical microscopy (OM) (Carl Zeiss AG, Jena, Germany), scanning electron microscopy (SEM) (FEI, Hillsboro, OR, USA), and transmission electron microscopy (TEM) (JEOL, Tokyo, Japan). Metallographic specimens were mechanically polished and etched in a 4 vol.\% Nital solution and then observed by Zeiss Axio Scope A1 optical micrographs. Secondary electron (SE) imaging was carried out using Nova 400 Nano SEM operated at $10 \mathrm{kV}$. The SEM samples were treated in the same way as the OM metallographic specimens. TEM was carried out in a JEM $2100 \mathrm{~F}$ TEM operated at $200 \mathrm{kV}$. The volume fraction of 
austenite was determined by X-ray diffraction (XRD) using a Bruker X'Pert Pro powder diffractometer (Bruker, Karlsruhe, Germany) with $\mathrm{CuK} \alpha$ radiation using direct comparison method [16], using peak search, the diffraction spectrum angle, half width, and integral intensity. The austenite (200), (220), and (311) plane diffraction lines and the diffraction lines of ferrite (200) and (211) planes were selected and used in equation (1) to calculate the retained austenite volume fraction [17].

$$
V_{\gamma}=1.4 I_{\gamma} /\left(I_{\alpha}+1.4 I_{\gamma}\right)
$$

where $V_{\gamma}$ is the volume fraction of retained austenite, $I_{\gamma}$ is the integrated intensity of austenite peaks, and $I_{\alpha}$ is the integrated intensity of the ferrite peaks. The contents of $C$ and $\mathrm{Mn}$ in austenite at different temperatures were studied using Thermo-Calc (a popular software package for thermo kinetics) combined with TCFE7 database. The phase composition of each temperature in the equilibrium state and the weight percentage of each alloying element in austenite at different temperatures were calculated using Thermo-Calc. 2017b (Thermo-Calc Software, Stockholm, Sweden).

\section{Results and Discussion}

\subsection{Microstructure and Mechanical Properties}

The microstructures of the cold-rolled and heat-treated samples are shown in Figure 3. After the addition of Mo, the middle manganese steel increased in hardenability, leading to formation of fine quenched martensite in some austenite grains. The grains gradually refined and banded during annealing at $600-650{ }^{\circ} \mathrm{C}$, with the prior austenite grain boundaries visible (Figure $3 \mathrm{a}-\mathrm{C}$ ). Grain recovery occurred at $675-750{ }^{\circ} \mathrm{C}$ in the cold rolled structure as the annealing temperature increased, the martensite plates were completely recovered at $750{ }^{\circ} \mathrm{C}$, and the grains were gradually coarsened with increase in annealing temperature (Figure $3 \mathrm{~d}-\mathrm{f}$ ).

The SEM micrographs at annealing temperatures in the range of $600-750{ }^{\circ} \mathrm{C}$ are shown in Figure 4 . Figure $4 \mathrm{a}-\mathrm{e}$ describes the microstructure of samples quenched from $600{ }^{\circ} \mathrm{C}, 625{ }^{\circ} \mathrm{C}, 650{ }^{\circ} \mathrm{C}, 675{ }^{\circ} \mathrm{C}$, and $700{ }^{\circ} \mathrm{C}$ respectively. The microstructure mainly consisted of a fine ferrite $(\mathrm{F})$ phase and a retained austenite (RA) when the quenching temperature ranged from $600{ }^{\circ} \mathrm{C}$ to $700{ }^{\circ} \mathrm{C}$. When the sample was quenched from $750{ }^{\circ} \mathrm{C}$ (see Figure 4f), the microstructure of the experimental steel was blocked austenite, ferrite, and martensite. Since blocked austenite was unstable, austenite content dropped to a lower level (see also Figure 6c). As the quenching temperature increased, the austenite grain size increased and the content of $\mathrm{C}$ and Mn decreased, resulting in a decrease in austenite stability, rendering austenite more likely transform into martensite. The austenite is significantly reduced due to extensive martensitic (M) transformation. It was noteworthy that the severely deformed microstructure after cold rolling developed into a band-like morphology.

The weight percentages of $\mathrm{Mn}, \mathrm{C}, \mathrm{Al}, \mathrm{Mo}$, and $\mathrm{Nb}$ in face centered cubic (FCC) phase, and representation austenite were calculated by Thermo-Calc. (see Figure 5). In the annealing temperature range of $600-750{ }^{\circ} \mathrm{C}$, the Mn content in austenite decreasedfrom $14.4 \mathrm{wt} . \%$ to $6.3 \mathrm{wt} . \%$ (see Figure 5a). C content in austenite at $625{ }^{\circ} \mathrm{C}, 650{ }^{\circ} \mathrm{C}$, and $675{ }^{\circ} \mathrm{C}$ was 0.394 wt.\%, 0.391 wt. $\%$, and 0.343 wt. $\%$, respectively. Thus, compared to $\mathrm{C}, \mathrm{Mn}$ played a more important role in austenite stability at room temperature. The experimental steel at the annealing temperature of $750{ }^{\circ} \mathrm{C}$ resulted in a significant decrease in the thermal stability of austenite due to insufficient Mn enrichment. Simultaneously, the contents of $\mathrm{Al}$ and $\mathrm{Mo}$ in austenite were in the range of $0.248-0.571$ in wt.\%, 0.06-0.167 in wt.\%, respectively, lower than the nominal chemical composition (see Figure 5b). 


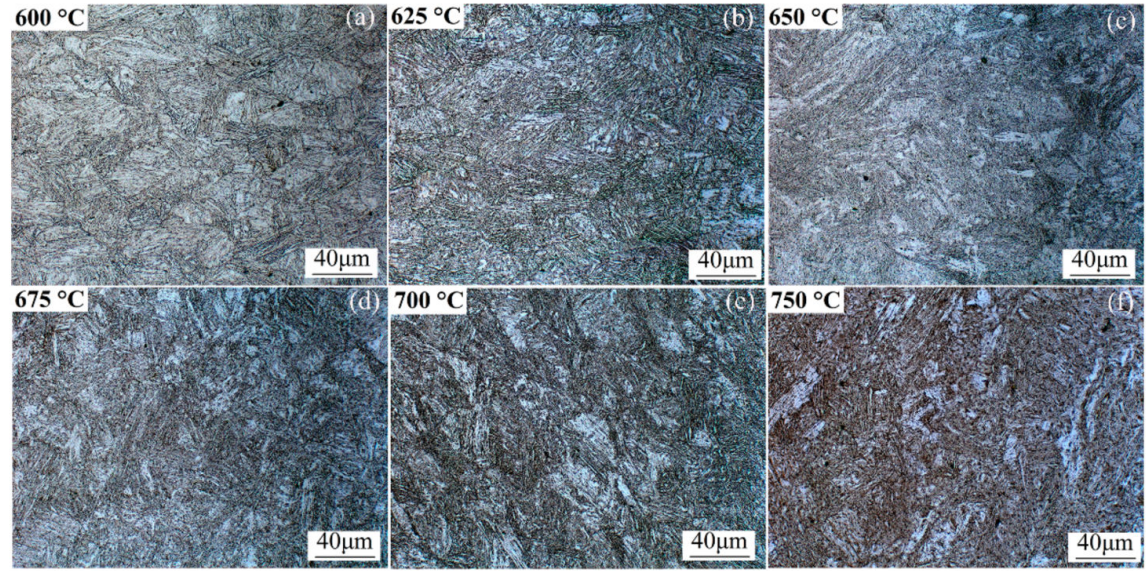

Figure 3. Optical micrographs of experimental steels at different annealing temperatures. (a) $600{ }^{\circ} \mathrm{C}$, (b) $625^{\circ} \mathrm{C}$, (c) $650{ }^{\circ} \mathrm{C}$, (d) $675{ }^{\circ} \mathrm{C}$, (e) $700{ }^{\circ} \mathrm{C}$, and (f) $750{ }^{\circ} \mathrm{C}$.
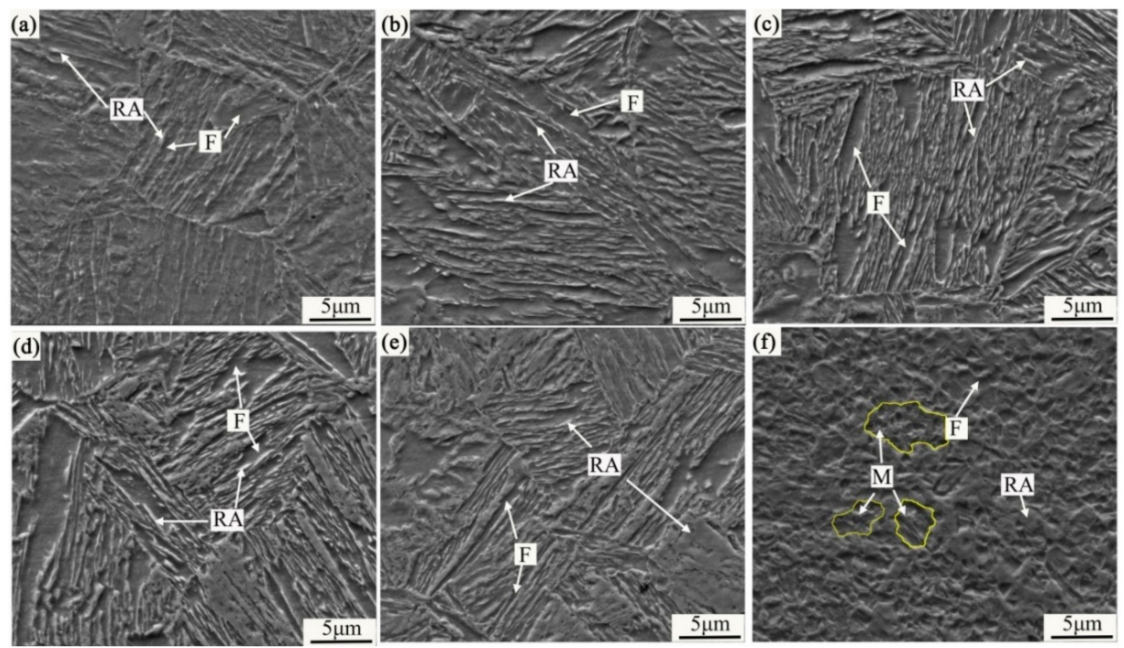

Figure 4. SEM micrographs of experimental steels at different annealing temperatures. (a) $600{ }^{\circ} \mathrm{C}$, (b) $625^{\circ} \mathrm{C}$, (c) $650^{\circ} \mathrm{C}$, (d) $675^{\circ} \mathrm{C}$, (e) $700{ }^{\circ} \mathrm{C}$, and (f) $750^{\circ} \mathrm{C}$ (F, ferrite; RA, retained austenite; M, martensite).
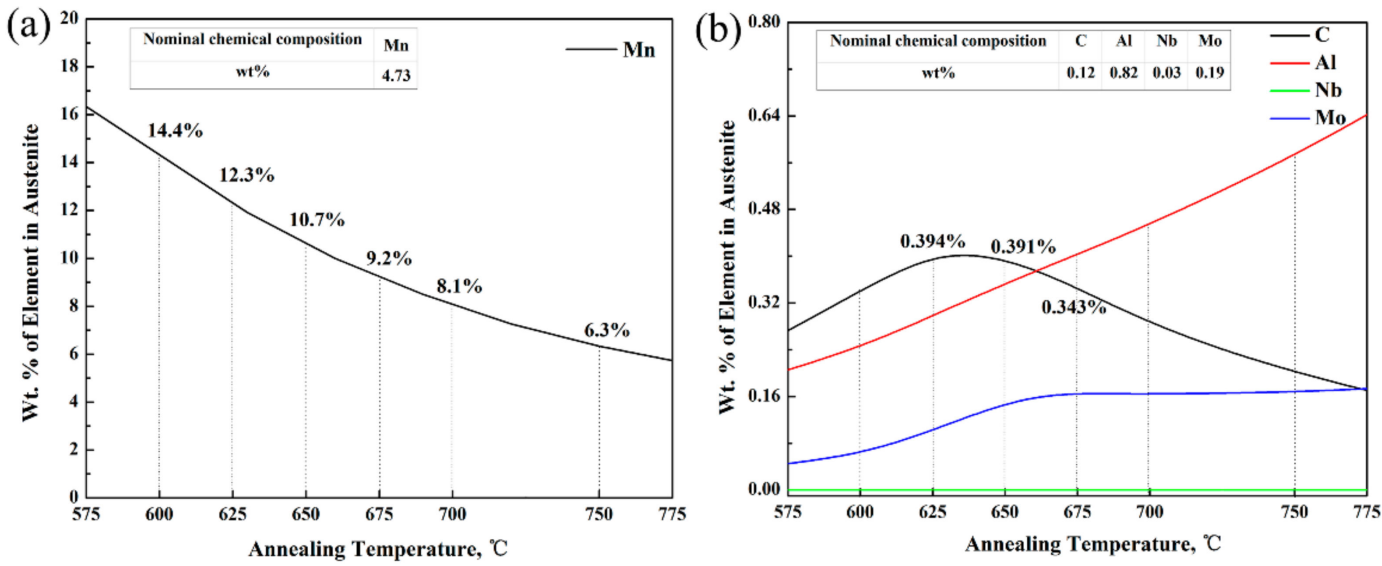

Figure 5. Calculated weight percent of $\mathrm{Mn}, \mathrm{C}, \mathrm{Al}, \mathrm{Mo}$, and $\mathrm{Nb}$ in austenite by Thermo-Calc. (a) $\mathrm{Mn}$, (b) $\mathrm{C}, \mathrm{Al}, \mathrm{Mo}$, and $\mathrm{Nb}$ in austenite by Thermo-Calc. 
Figure 6 shows the XRD pattern and measured austenite fraction of the experimental steels at different annealing temperatures. The RA fractions of $\mathrm{V}_{\gamma}$ were calculated using Equation (1) from Figure $6 \mathrm{a}, \mathrm{b}$ (see Figure $6 \mathrm{c}$ ). The austenite content in the experimental steel had a maximum of $\sim 39$ vol. $\%$ at the annealing temperature of $650{ }^{\circ} \mathrm{C}$. As the annealing temperature increased to $750{ }^{\circ} \mathrm{C}$, it decreased to a minimum of $\sim 20$ vol.\% due to martensite transformation (see also Figure $4 \mathrm{f}$ ). The transformation ratio of austenite is shown in Figure $6 \mathrm{c}$. The maximum austenite transformation ratio in the experimental steel at an annealing temperature of $650{ }^{\circ} \mathrm{C}$ (hence forth referred as the $650{ }^{\circ} \mathrm{C}$ sample) was about $87 \%$ and the minimum austenite transformation rate in the $750{ }^{\circ} \mathrm{C}$ sample was about $55 \%$. The transformation ratio of austenite will be discussed in relation to TRIP effect later.
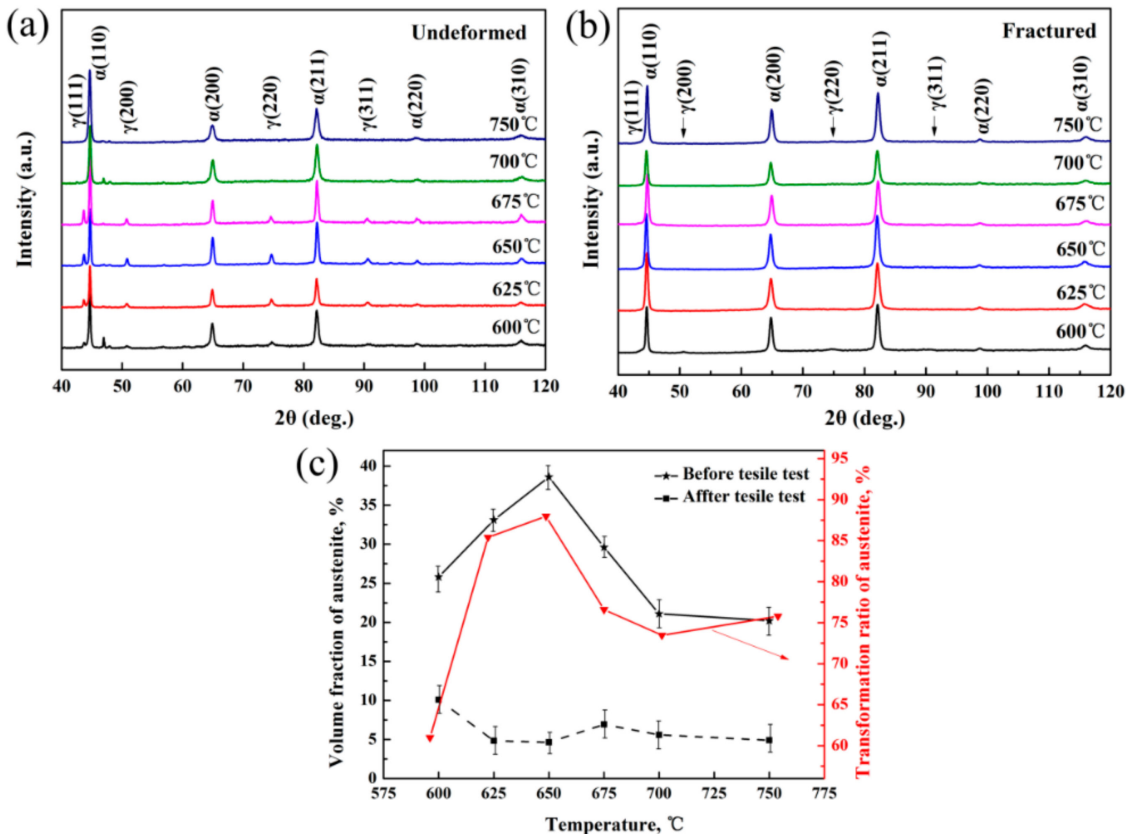

Figure 6. XRD pattern and measured austenite fraction of experimental steels at different annealing temperatures: (a) undeformed, (b) fractured, (c) austenite fraction calculated using Equation (1) and transformation ratio of austenite.

Tensile properties of experimental steels at different annealing temperatures are summarized in Figure 7. The ultimate tensile strength (UTS) reached a maximum value of $1373 \mathrm{MPa}$ as the intercritical annealing temperature increased to $750{ }^{\circ} \mathrm{C}$. Meanwhile, the total elongation (TE) reached a maximum of $40 \%$, with the intercritical annealing temperature rising to $650{ }^{\circ} \mathrm{C}$, and then decreased with a further increase in temperature (see Figure $7 \mathrm{~b}$ ). As shown in Figures $6 \mathrm{c}$ and $7 \mathrm{~b}$, TE variation remained the same as that of austenite, suggesting that the elongation of experimental steel was closely related to austenite content. The product of ultimate tensile strength and total elongation reached a maximum value of $41.0 \mathrm{GPa} \%$ at $650{ }^{\circ} \mathrm{C}$ (see Figure $7 \mathrm{c}$ ). On the other hand, the yield strength reached a minimum of 659 $\mathrm{MPa}$ at the annealing temperature of $675^{\circ} \mathrm{C}$. As is shown in Figure $4 \mathrm{a}-\mathrm{d}$, the yield strength gradually decreased as the annealing temperature increased from $600{ }^{\circ} \mathrm{C}$ to $675^{\circ} \mathrm{C}$ due to the softening effect of ferrite phase. In contrast, the hardening effect of the hard phase martensite formed in the material after the annealing temperature was increased from $675^{\circ} \mathrm{C}$ to $750{ }^{\circ} \mathrm{C}$, contributing to the rebound of the yield strength. The $650{ }^{\circ} \mathrm{C}$ sample, characterized by elongation of $40 \%$, ultimate tensile strength of $1025 \mathrm{MPa}$, UTS $\times$ TE of $41 \mathrm{GPa} \%$, and yield ratio of 0.67 exhibited the best tensile properties which were significantly superior to the values reported for the medium-Mn TRIP steels of a similar chemical composition [18]. The reasons underlying the superior mechanical properties of the sample quenched at $650{ }^{\circ} \mathrm{C}$ can be further elucidated by studying austenite stability and its work-hardening behavior. 

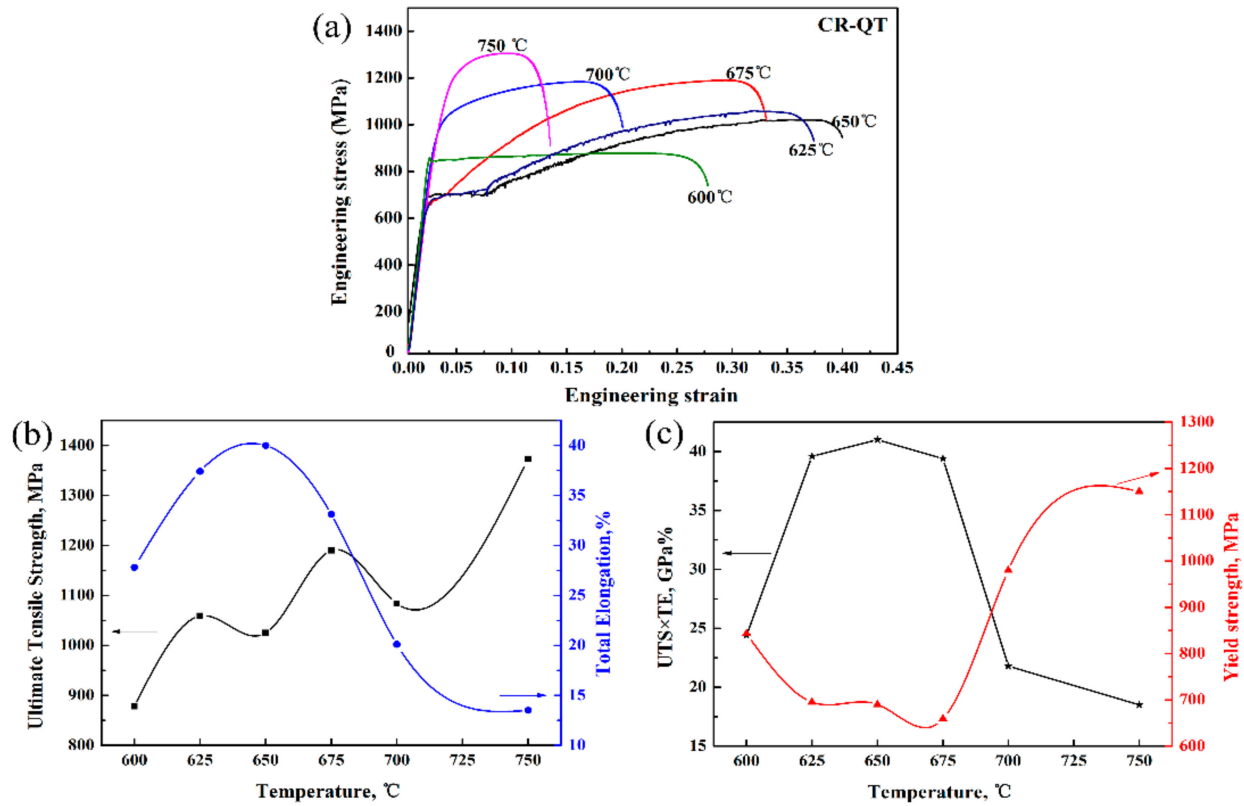

Figure 7. Tensile properties of experimental steels at different annealing temperatures. (a) engineering stress-strain curves, (b) ultimate tensile strength and total elongation and (c) UTS $\times$ TE and yield strength. (UTS $\times$ TE: product of ultimate tensile strength and total elongation).

\subsection{Austenite Stability and Work-Hardening Behavoir}

Among the $625^{\circ} \mathrm{C}, 650{ }^{\circ} \mathrm{C}$, and $675^{\circ} \mathrm{C}$ samples, the $650{ }^{\circ} \mathrm{C}$ sample contained the largest amount of austenite with $39 \mathrm{vol} . \%$, with $87 \%$ transforming to martensite after fracture. In contrast, the $625{ }^{\circ} \mathrm{C}$ and $675{ }^{\circ} \mathrm{C}$ samples comprised 33.1 and 29.6 vol.\% austenite, respectively (Figure 6c), while their austenite transformation rates after fracture were $79 \%$ and $84 \%$, respectively. Figure $7 \mathrm{~b}$ shows that the UTS $\times$ TE is closely related to the content of austenite. Retained austenite, the source of the TRIP effect, plays a significant role in the multiphase structure of medium manganese TRIP steel. A prerequisite for this is that the microstructure contained a certain amount of retained austenite with a certain degree of stability. Austenite stability entails thermal stability and mechanical stability. The former is mainly affected by the chemical composition of the material and the heat treatment schedule $[19,20]$ It hinges upon the interplay of internal factors (chemical constituents, austenite grain size, and austenite distribution characteristics, etc.) and external factors (heat treatment schedule, deformation temperature, deformation rate, and stress state, etc.) to result in hysteresis of austenite transformation into martensite. Mechanical stability of austenite is mainly related to deformation temperature, deformation rate, and stress state and can often be calculated by using the following equation [21]:

$$
f_{\gamma}=f_{\gamma 0} \exp (-k \varepsilon)
$$

In Equation (2), $f_{\gamma}, f_{\gamma 0}$, and $k$ are austenite fraction at strain $\varepsilon$, initial austenite fraction, and mechanical stability of austenite, respectively. Generally, austenite stability increases as $k$ value decreases [7]. In this study, the $k$ parameter curve of experimental steel samples at different annealing temperatures was $600{ }^{\circ} \mathrm{C}(k=3.4)<675^{\circ} \mathrm{C}(k=4.1)<625^{\circ} \mathrm{C}(k=5.3)<650{ }^{\circ} \mathrm{C}(k=5.4)<700^{\circ} \mathrm{C}(k=6.6)$ $<750{ }^{\circ} \mathrm{C}(k=10.5)$ in descending order (see Figure 8). Admittedly, the tensile properties of the samples did not align well with their $k$ parameter, with $650^{\circ} \mathrm{C}>625^{\circ} \mathrm{C}>675^{\circ} \mathrm{C}>700{ }^{\circ} \mathrm{C}>750{ }^{\circ} \mathrm{C}>625^{\circ} \mathrm{C}$ in descending order (see Figure 8). Most noticeably, the $650^{\circ} \mathrm{C}$ sample excelled tensile properties because of its appropriate austenite stability. This is because the largest amount of austenite was produced within the sample at this temperature, a reason also applicable to other samples except the $600{ }^{\circ} \mathrm{C}$ one whose excessive austenite stability, as reflected by its $k$ parameter, prevented austenite from 
transforming into martensite, ultimately hindering enhancement in tensile properties. These findings suggest tensile properties are closely related to austenite stability regardless of the interference of other factors.

Austenite stability can be reflected via the work-hardening rates (WHR) during the tensile process. The WHR of the three samples with comparatively better tensile properties are presented in Figure 9, with those of the samples of $625^{\circ} \mathrm{C}$ and $650{ }^{\circ} \mathrm{C}$ rather similar. Austenite in the $650{ }^{\circ} \mathrm{C}$ sample with low stability $(k=5.4)$ transformed at a relatively smaller strain $(\varepsilon<0.025)$ while the austenite in the $675^{\circ} \mathrm{C}$ sample with high stability $(k=4.1)$ transformed at a larger strain $(\varepsilon<0.03)$. The majority of austenite was retained after tensile test among the three samples (consistent with Figure 6). These results suggest that the outstanding ductility of the $650{ }^{\circ} \mathrm{C}$ sample is primarily associated with the TRIP effect, whereas the ductility of the $675{ }^{\circ} \mathrm{C}$ sample is mainly related to ferrite deformation. It is desirable that the microstructure contains more retained austenite with appropriate stability and that austenite-to-martensitic transformation occurs gradually as the strain increases. In this study, the $650{ }^{\circ} \mathrm{C}$ sample $(k=5.4)$ had the largest amount of austenite with appropriate stability, thus enjoying the best tensile properties.

The WHR can be divided to four stages (see Figure 9). The WHR decreased rapidly in stage 1 (S1), remained rather stable until its fluctuation in S2, then varied considerably as true strain increased in S3, and finally decreased in a serrated manner in S4. The WHR performance in four stages can be explained by: soft phase ferrite underwent considerable yield deformation in the early stage of plastic deformation (S1) [22,23]; there was a competition between the strength increasing effect caused by the TRIP effect of retained austenite and the softening effect of ferrite deformation (S2) [24]; the progressive TRIP effect of retained austenite caused the strength increasing effect to overcome the softening effect of ferrite deformation (S3) [25-28]; and the austenite TRIP effect was exhausted due to its negation, similar to S1, at the end of the strain (S4). It was noteworthy that the WHR peaks nearly disappeared with serrated behavior in S4. The enhanced TRIP effect could not compensate for the failure of a large plastic deformation within the microstructures, resulting in a reduction in the work-hardening rate [24].

Therefore, we may infer that the relatively poor tensile properties of the $675{ }^{\circ} \mathrm{C}$ sample resulted from the fact that the softening effect of ferrite was slightly greater than the hardening contribution of the TRIP effect (see Figure 9c). In contrast, the excellent ductility of the $625{ }^{\circ} \mathrm{C}$ and $650{ }^{\circ} \mathrm{C}$ samples seemed to be primarily associated with the discontinuous TRIP effect (see Figure 9a,b), with austenite content in the $650{ }^{\circ} \mathrm{C}$ sample higher than the $625^{\circ} \mathrm{C}$ one. The amount of austenite can directly influence the exertion of TRIP effect, which in turn caused difference in the mechanical properties of the two samples (see also Figure 6c).

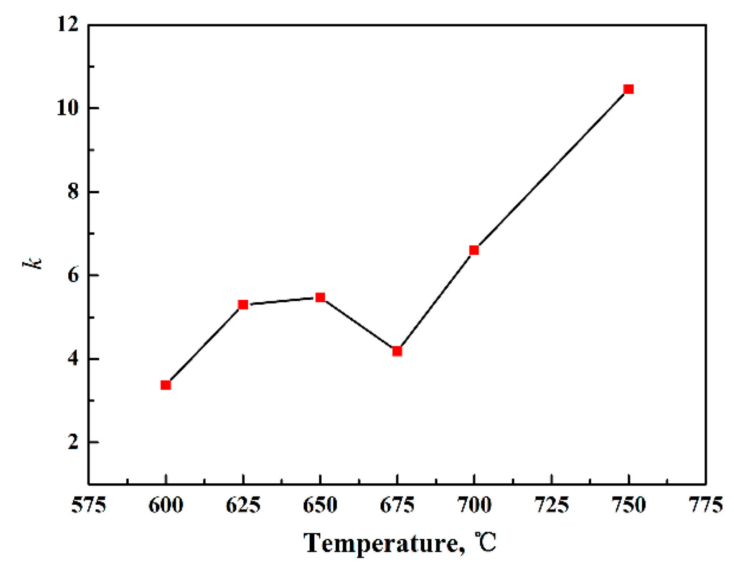

Figure 8. Plots of the $k$ parameter of samples intercritical annealing at different temperatures. 

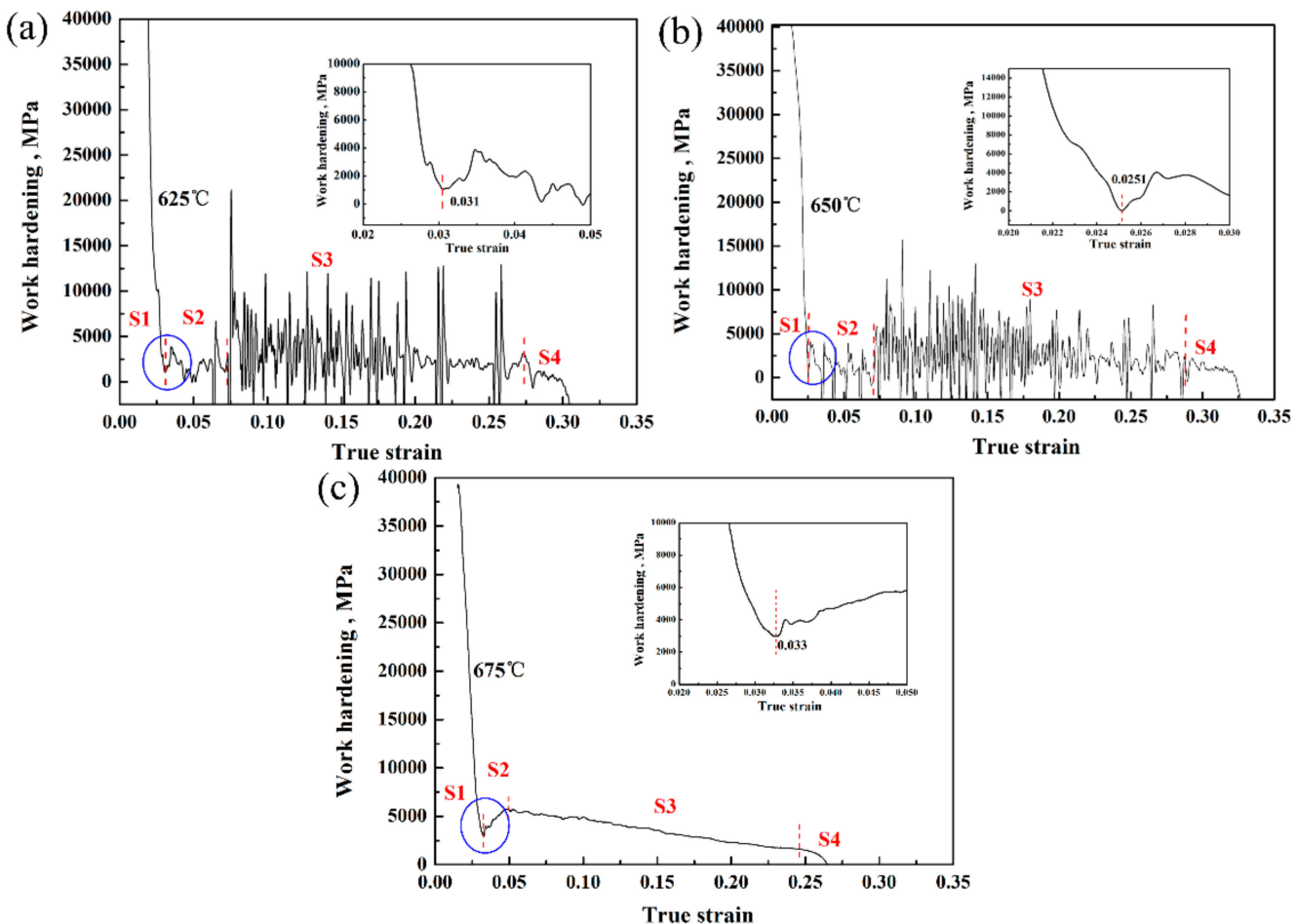

Figure 9. Work-hardening rate of samples at annealing temperatures at (a) $625{ }^{\circ} \mathrm{C},(\mathbf{b}) 650{ }^{\circ} \mathrm{C}$, and (c) $675{ }^{\circ} \mathrm{C}$.

\subsection{Effect of Temperatures on Lïders Bands and Discontinuous TRIP Effect}

During the deformation process of the samples, the stress-strain curve of the steel showed two characteristic phenomena, namely the yielding platform and the discontinuous TRIP effect (see Figure 10). The yielding platform phenomenon seemed to be related to Lüders band formation (see Figure 10a). Lüders band formation was generally attributed to the high-density dislocations and explained by Cottrell-Bilby theory $[29,30]$. It is considered to cause inhomogeneous deformation of local sudden yield of the sheet, resulting in wrinkle bands on the surface of the steel sheet [31]. The length of the Lüders bands at different annealing temperatures is shown in Figure 10a. The Lüders band started from the formation point and then spread out towards the unyielding area of the sample, as shown in the simplified case of 1-3 points. Obviously, the length of Lüders strain decreased as the annealing temperature increased.

WHR fluctuation corresponded to the serrated phenomenon present on the true stress-strain curve, which might be related to the release and concentration of the local stress by the TRIP effect. Figure $10 \mathrm{~b}$ shows the WHR and the true strain-stress curve of the $650{ }^{\circ} \mathrm{C}$ sample. S3 in Figure $10 \mathrm{~b}$ shows that martensitic transformation was activated when a critical strain of 0.079 was achieved and then transformation occurred continuously in the retained austenite of similar stability with an instantaneous WHR peak 1 (P1) Simultaneously, the corresponding steep increase in true stress was obtained. When the strain formed peak points P1 to P2, the true stress gradually increased and the WHR remained almost unchangeable due to the limited or even stoppage of TRIP effect because of the small amount of retained austenite. With further increasing deformation, the accumulated true strain reached another critical strain (0.089), activating partial retained austenite with a relatively high degree of stability to undergo concentrative transformation. Thus, a new round of TRIP effect was initiated, resulting in a new instantaneous WHR peak point, $\mathrm{P} 2$, and a substantial increase in true stress. 

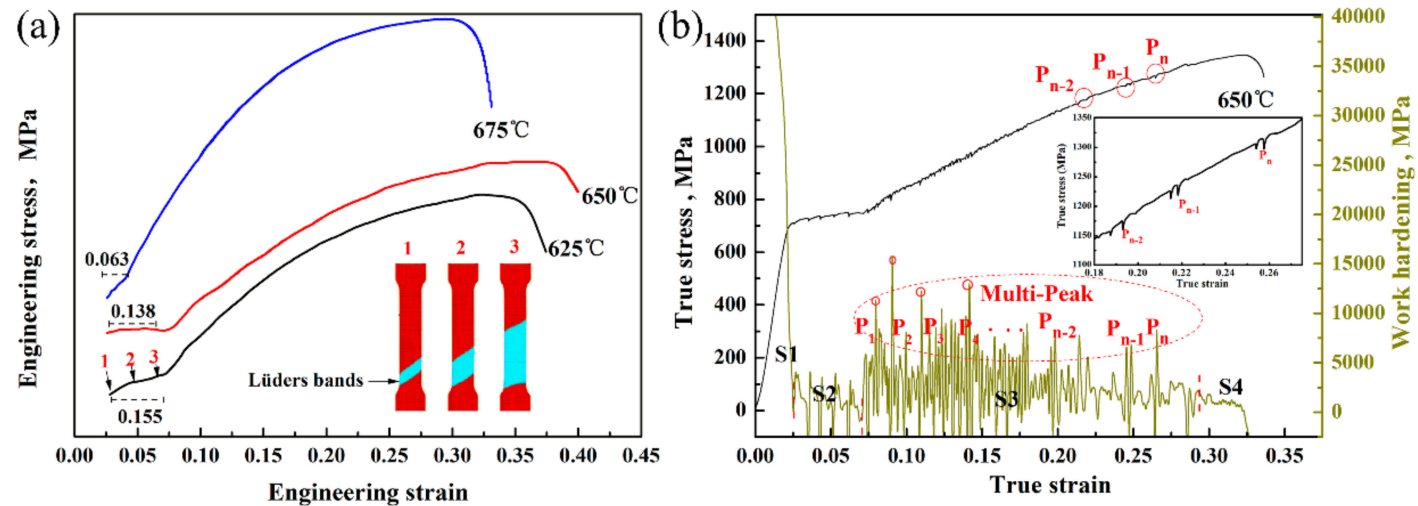

Figure 10. Variation of (a) length of Lüders strain at different temperatures, (b) Work-hardening rate and true strain-stress plot of sample heat treated at $650^{\circ} \mathrm{C}$.
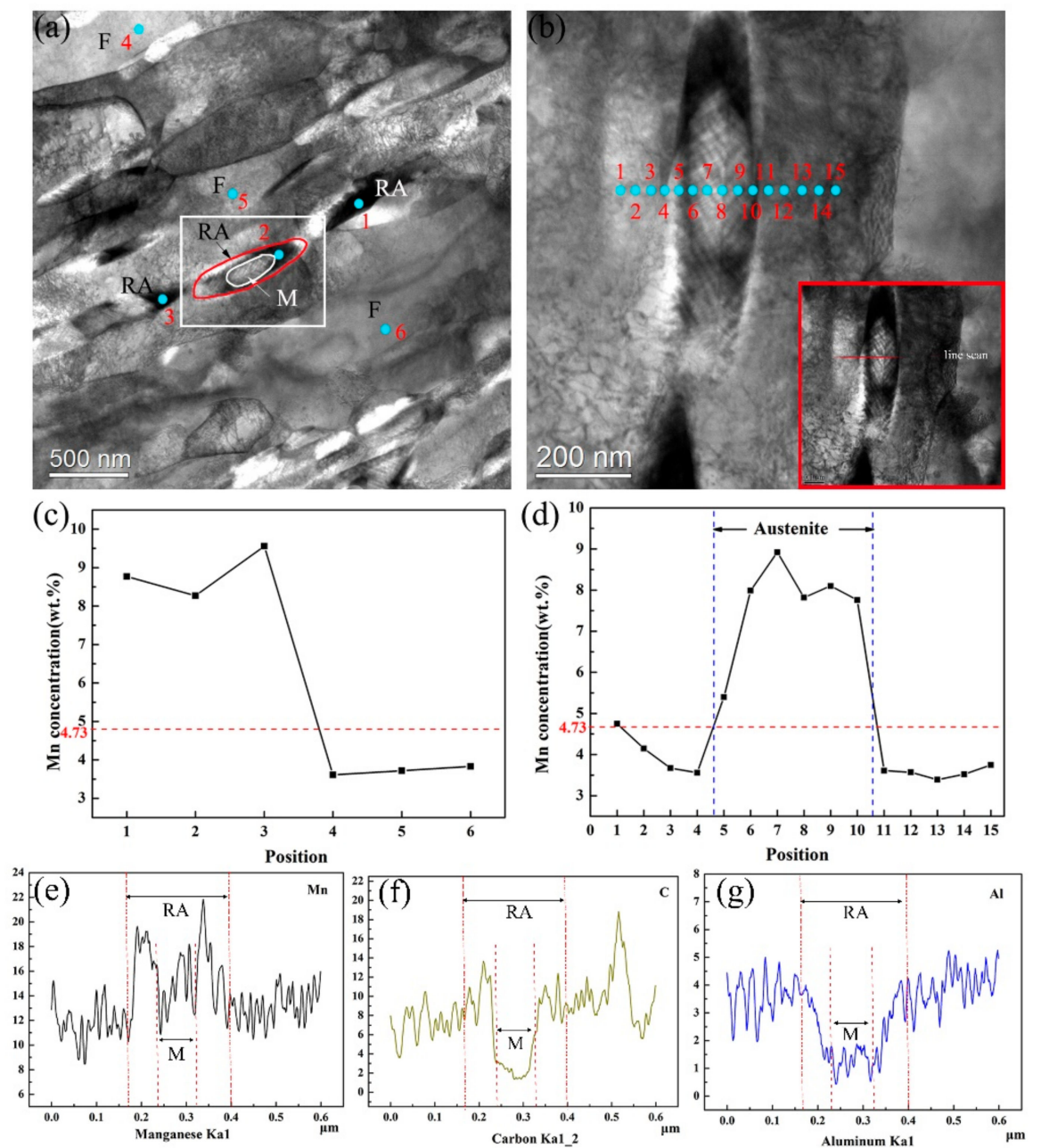

Figure 11. TEM micrograph and EDS analysis showing evidence of Mn partitioned among austenite, ferrite, and martensite: (a) TEM micrograph of the $650{ }^{\circ} \mathrm{C}$ sample; (b) TEM micrograph of the area denoted by white square in (a); (c) manganese partitioned in austenite and ferrite of the $650{ }^{\circ} \mathrm{C}$ sample in (a); (d) manganese partitioned among austenite, ferrite, and martensite of the $650{ }^{\circ} \mathrm{C}$ sample in (b); (e-g) Line scan of the area denoted by red square in (b) for $\mathrm{Mn}, \mathrm{C}$, and $\mathrm{Al}$, respectively. F, ferrite; RA, retained austenite; $\mathrm{M}$, martensite; Red coordinates 4.73 , the nominal chemical composition of $\mathrm{Mn}$. 
Factors significantly affecting austenite stability include chemical composition, heat treatment schedule, distribution characteristics, and so on [19,32-34]. Particularly, the chemical composition has an impressive influence on austenite stability. $\mathrm{C}$ and $\mathrm{Mn}$ can greatly increase austenite stability at room temperature [20,35]. Mn partitioning among austenite, ferrite, and martensite of the $650{ }^{\circ} \mathrm{C}$ sample is shown in Figure 11. Mn distribution appeared higher in austenite grains than in ferrite grains, suggesting that Mn diffused from ferrite to austenite during annealing (see Figure 11a-d). The average Mn content of 12 austenite grains was $8.0 \pm 0.3 \mathrm{wt} . \%$ and $3.7 \pm 0.6 \mathrm{wt} . \%$ for 17 ferrite grains; the nominal Mn content in the alloys was $4.73 \mathrm{wt} . \%$ and the calculated equilibrium $\mathrm{Mn}$ at $650{ }^{\circ} \mathrm{C}$ was $10.6 \mathrm{wt} . \%$. The Mn contents in austenite did not reach levels that correspond to full partitioning. These results indicate that the redistribution of Mn during intercritical annealing is not appreciable, probably due to the short annealing time. Furthermore, the Mn content in martensite seemed similar to that in austenite grains (see Figure 11e-g and $11 \mathrm{~b}$ for $\mathrm{Mn}, \mathrm{C}$, and $\mathrm{Al}$, respectively). Mn content in fresh martensite grains was slightly lower than that in retained austenite grains (Figure 11e). In contrast, $\mathrm{C}$ and $\mathrm{Al}$ contents in fresh martensite grains were significantly lower than those in austenite grains, while $\mathrm{Al}$ content in ferrite grains was higher than that in austenite grains (Figure 11f,g). Presumably martensite grains were transformed during quenching from the austenite grains with similar $\mathrm{Mn}$ content but lower $C$ content. The effect of chemical composition, particularly carbon and manganese content, can be described in terms of chemical driving force for martensitic transformation in the following equation [36]:

$$
\Delta G^{c h}=-7381.6+69447 X_{c}+19296 X_{M n}-38776 X_{C} X_{M n}+\left(6.7821-33.45 X_{C}\right) T
$$

$\Delta G^{c h}$ is the chemical driving force of martensitic transformation, $X_{C}$ and $X_{M n}$ are the mole fraction of carbon and manganese in austenite respectively, and $T$ is the temperature in Kelvin. The chemical driving force of martensitic transformation is shown in Figure 12. The mole fractions of $C$ and $M n$ were calculated by Thermo-Calc. in combination with TCFE7 database and the chemical driving force of martensite transformation was calculated by Equation (3). Both $\mathrm{C}$ and $\mathrm{Mn}$ appeared effective stabilizers for austenite with higher $C$ and $M n$ content contributing together austenite stability. Generally, the content of $C$ in the retained austenite must be controlled within the range of $0.5 \mathrm{wt} . \% \sim 1.8 \mathrm{wt} . \%$, the higher content of $C$ in retained austenite results in its better stability.

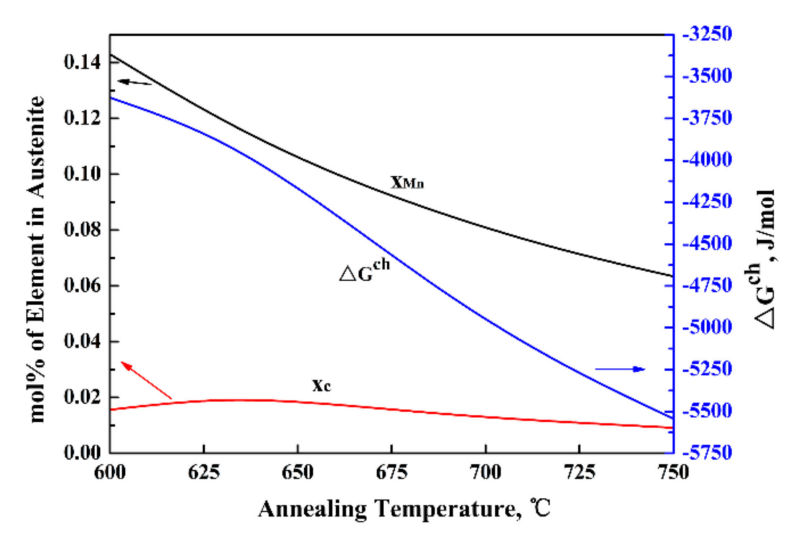

Figure 12. Chemical driving force diagram of martensitic transformation.

\subsection{Influence of Nb Alloying Onmicrostructure and Tensile Properties}

Figure 13a,c shows the TEM microstructure with $\mathrm{NbC}$ precipitates of the $650{ }^{\circ} \mathrm{C}$ sample. Certain $\mathrm{NbC}$ precipitates in the ferrite grains with grain size of about $36.2 \mathrm{~nm}$ (Figure 13b) hindered dislocation movement and played a role in precipitation strengthening. An $\mathrm{NbC}$ precipitate in the dislocation line has a pinning effect which hindered dislocation motion during the deformation process $[37,38]$. This requires more external force to overcome the pinning effect of the deposit 
on dislocations and ultimately increases the strength of the matrix by bypassing or shearing the precipitates to generate dislocations. A caveat is in order here. The influence of $\mathrm{NbC}$ precipitates of the samples other than the $650{ }^{\circ} \mathrm{C}$ one on the mechanical properties of the medium Mn steel requires further study.

Figure 14a schematically shows the evolution of ferrite formation during deformation in the steel without $\mathrm{Nb}$. With the increase of deformation, a large amount of ferrite grains were formed in the austenite grains and grain boundaries, and continuously recrystallized. Figure 14b shows the microstructure evolution of the experimental steel during deformation. At the beginning of deformation, a small amount of film-like ferrite was formed along the austenite grain boundaries. However, as the deformation increased further, the ferrite transformation hardly proceeded. The solute $\mathrm{Nb}$ was mainly enriched at ferrite and austenite grain boundaries. The strength-ductility product of the present $\mathrm{Mo}-\mathrm{Nb}$ micro-alloyed TRIP steel was approximately twice that of the Fe-0.1C-5Mn alloy [39], which was attributable to austenite hardenability, grain refinement, and nanoprecipitation hardening by $\mathrm{Nb}$ and Mo additions, in addition to the TRIP effect. The critical driving force for the precipitate of ferrite nucleation given by Equation (4) below was reduced [40]. Thus, the strain-induced driving force for the ferrite formation was consumed by $\mathrm{NbC}$ precipitation during the deformation process. Therefore, $\mathrm{Nb}$, having precipitated in the form of $\mathrm{NbC}$ particles in the crystal, not only played a role in impeding high-intensity motion of dislocations, but also delayed the transformation of austenite to ferrite due to its segregation effect at the austenite and ferrite grain boundaries. In summary, the $\mathrm{Nb}$ contributed to grain refinement and precipitation strengthening.

$$
\Delta G_{v}=\Delta G_{c h}+\Delta G_{s t}
$$

$\Delta G_{v}$ is the critical driving force for the precipitate of ferrite nucleation, $\Delta G_{c h}$ is the chemical driving force of ferrite and $\Delta G_{s t}$ is the strain-induced driving force of ferrite.
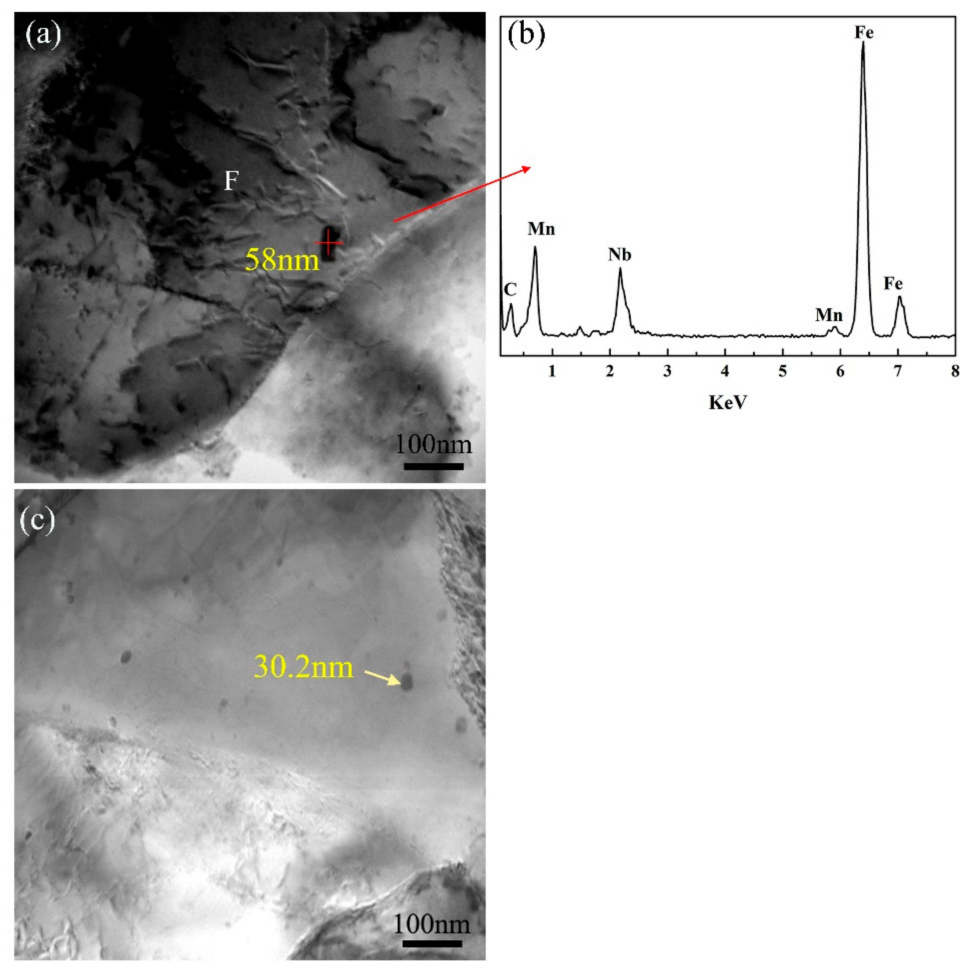

$\mathrm{KeV}$

Figure 13. (a) TEM Microstructure of $\mathrm{NbC}$ precipitates with grain size of about $58 \mathrm{~nm}$ of the $650{ }^{\circ} \mathrm{C}$ sample, (b) EDX spectra of $\mathrm{NbC}$ precipitates in (a), (c) TEM Microstructure of $\mathrm{NbC}$ precipitates with grain size of about $30.2 \mathrm{~nm}$ of the $650{ }^{\circ} \mathrm{C}$ sample. $\mathrm{F}$, ferrite. 


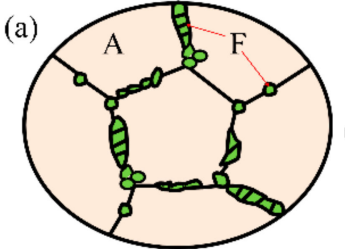

the steel without $\mathrm{Nb}$

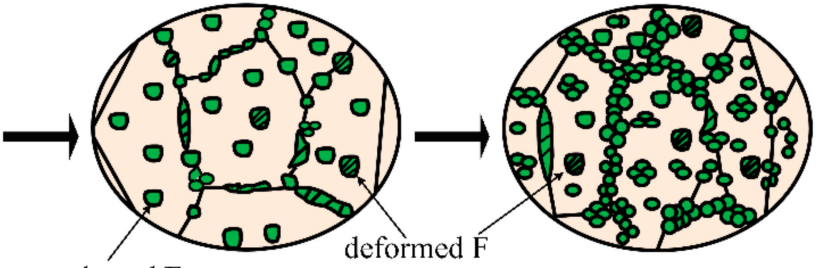

nucleated $\mathrm{F}$ (b)

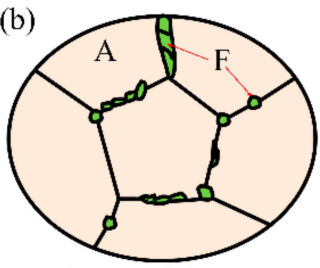

$\mathrm{Nb}$-containing steel

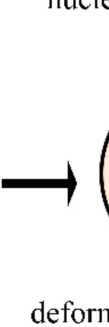

deformed $\mathrm{F}$

Increasing deformation

Figure 14. Schematic diagrams of microstructural evolution during deformation. (a) Based on the microstructural evolution data of experimental steel without $\mathrm{Nb}$ element in Reference [39]. (b) Nb-containing steel of the $650{ }^{\circ} \mathrm{C}$ sample.

\section{Conclusions}

In this study, we investigated the microstructures, tensile properties, and austenite stability of the $\mathrm{Nb}$ and Mo micro-alloyed medium Mn steels with a total alloying addition of less than $6 \mathrm{wt.} \%$. We have come to the following conclusions: (a) The steel subjected to $Q$ \& $T$ and quenched from $650{ }^{\circ} \mathrm{C}$ for 30 min exhibits the best comprehensive properties with a high volume fraction of austenite $(\sim 39 \%)$, and is characterized by an excellent combination of TE of $40 \%$, UTS of $1025 \mathrm{MPa}$, and UTS $\times$ TE of $41 \mathrm{GPa} \%$; (b) The optimal mechanical properties of the $650{ }^{\circ} \mathrm{C}$ sample are primarily associated with the discontinuous TRIP effect and secondarily with the cooperative softening effect of ferrite deformation. Austenite in the $650{ }^{\circ} \mathrm{C}$ sample has appropriate stability for gradual strain-induced austenite-martensite transformation; (c) Lüders strain decreased in length with an increase in the annealing temperature. The higher stability of austenite was attributable to higher $\mathrm{C}$ and Mn enrichment; (d) Nb impedes the high intensity motion of dislocations, and delays the transformation of austenite to ferrite while Mo increases the hardenability of experimental steel. The micro-alloyed medium manganese steel experimented in our study showed considerable improvement in tensile properties in comparison with the $5 \mathrm{Mn}-0.1 \mathrm{C}$ medium manganese steel in previous studies.

Author Contributions: Conceptualization, C.L., Q.P., and Z.X.; Methodology, C.L., M.D., S.W., and C.Y.; Writing-Original Draft Preparation, C.L. and Z.X.; Writing-Review \& Editing, C.L., M.D., S.W. and C.Y.; Project Administration, Q.P.

Funding: This research received no external funding.

Acknowledgments: We thank Na Luo for her extremely helpful assistance in revising the manuscript. We also thank Hengyang Valin steel Tube Co, Ltd. (HYST) and China Bao Wu Wuhan Iron and Steel Group Co, Ltd. for technical assistance and financial support.

Conflicts of Interest: The authors declare no conflict of interest.

\section{References}

1. Pereloma, E.V.; Russell, K.F.; Miller, M.K.; Timokhina, I.B. Effect of pre-straining and bake hardening on the microstructure of thermo mechanically processed CMnSi TRIP steels with and without $\mathrm{Nb}$ and Mo additions. Scr. Mater. 2008, 58, 1078-1081. [CrossRef] 
2. Shi, X.Z. Analysing the application Trend of lightend Material to the Automobile Production. J. Liaoning Inst. Sci. Technol. 2009, 11, 10-14.

3. Raabe, D.; Ponge, D.; Dmitrieva, O.; Sander, B. Nanoprecipitate-hardened 1.5 GPa steels with unexpected high ductility. Scr. Mater. 2009, 60, 1141-1144. [CrossRef]

4. Kuzmina, M.; Ponge, D.; Raabe, D. Grain boundary segregation engineering and austenite reversion turn embrittlement into toughness: Example of a 9 wt.\% medium Mn steel. Acta Mater. 2015, 86, 182-192. [CrossRef]

5. Li, Z.C.; Ding, H.; Misra, R.D.K.; Cai, Z.H. Microstructure-mechanical property relationship and austenite stability in medium-Mn TRIP steels: The effect of austenite-reverted transformation and quenching-tempering treatments. Mater. Sci. Eng. A 2017, 682, 211-219. [CrossRef]

6. Zhao, X.; Shen, Y.; Qiu, L.; Liu, Y.; Sun, X.; Zuo, L. Effects of Intercritical Annealing Temperature on Mechanical Properties of Fe-7.9Mn-0.14Si-0.05Al-0.07C Steel. Materials 2014, 7, 7891-7906. [CrossRef] [PubMed]

7. Cai, Z.H.; Ding, H.; Misra, R.D.K.; Ying, Z.Y. Austenite stability and deformation behavior in a cold-rolled transformation-induced plasticity steel with medium manganese content. Acta Mater. 2015, 84, 229-236. [CrossRef]

8. Pereloma, E.; Gazder, A.; Timokhina, I. Retained Austenite: Transformation Induced Plasticity. In Encyclopedia of Iron, Steel and their Alloys; Taylor and Francis: New York, NY, USA, 2016; pp. 3088-3103.

9. Zurob, H.S.; Zhu, G.; Subramanian, S.V.; Purdy, G.R.; Hutchinson, C.R.; Brechet, Y. Analysis of the Effect of Mn on the Recrystallization Kinetics of High Nb Steel: An Example of Physically-based Alloy Design. ISIJ Int. 2005, 45, 713-722. [CrossRef]

10. Merwin, M. Microstructure and properties of cold rolled and annealed low-carbon manganese TRIP steels. Iron Steel Technol. 2008, 5, 6-84.

11. Timokhina, I.B.; Miller, M.K.; Pereloma, E.V. Microstructure-Property Relationship in the Thermo mechanically Processed C-Mn-Si-Nb-Al-(Mo) Transformation-Induced Plasticity Steels Before and After Prestraining and Bake Hardening Treatment. Metall. Mater. Trans. A 2012, 43, 2473-2483. [CrossRef]

12. Grajcar, A.; Kalinowska-Ozgowicz, E.; Opiela, M.; Grezgorczyk, B. Effects of Mn and Nb on the macro- and micro segregation in high-Mn high-Al content TRIP steels. Achiev. Mater. Sci. Eng. 2011, 49, 5-14.

13. Akben, M.G.; Bacroix, B.; Jonas, J.J. Effect of vanadium and molybdenum addition on high temperature recovery, recrystallization and precipitation behavior of niobium-based micro-alloyed steels. Acta Metall. 1983, 31, 161-174. [CrossRef]

14. Cai, M.; Li, Z.; Chao, Q.; Hodgson, P.D. A Novel Mo and Nb Micro-alloyed Medium Mn TRIP Steel with Maximal Ultimate Strength and Moderate Ductility. Metall. Mater. Trans. A 2014, 45, 5624-5634. [CrossRef]

15. Cai, Z.H.; Ding, H.; Xue, X.; Xin, Q.B. Microstructural evolution and mechanical properties of hot-rolled $11 \%$ manganese TRIP steel. Mater. Sci. Eng. A 2013, 560, 388-395. [CrossRef]

16. Haidemenopoulos, G.N.; Vasilakos, A.N. On the thermodynamic stability of retained austenite in 4340 steel. J. Alloys Compd. 1997, 247, 128-133. [CrossRef]

17. Jha, B.K.; Avtar, R.; Dwivedi, V.S. Structure-property correlation in low carbon low alloy high strength wire rods/wire containing retained austenite. Trans. Indian Inst. Met. 1996, 49, 133-142.

18. Suh, D.W.; Park, S.J.; Lee, T.H.; Oh, C.S.; Kim, S.J. Influence of Al on the Microstructural Evolution and Mechanical Behavior of Low-Carbon, Manganese Transformation-Induced-Plasticity Steel. Metall. Mater. Trans. A 2010, 41, 397. [CrossRef]

19. Moor, E.D.; Matlock, D.K.; Speer, J.G.; Merwin, M.J. Austenite stabilization through manganese enrichment. Scr. Mater. 2011, 64, 185-188. [CrossRef]

20. Lee, S.; Lee, S.J.; Cooman, B.C.D. Austenite stability of ultrafine-grained transformation-induced plasticity steel with Mn partitioning. Scr. Mater. 2011, 65, 225-228. [CrossRef]

21. Sugimoto, K.I.; Kobayashi, M.; Hashimoto, S.I. Ductility and strain-induced transformation in a high-strength transformation-induced plasticity-aided dual-phase steel. Metall. Trans. A 1992, 23, 3085-3091. [CrossRef]

22. Lee, C.Y.; Jeong, J.; Han, J.; Lee, S.J.; Lee, S.; Lee, Y.K. Coupled strengthening in a medium manganese lightweight steel with an in homogeneously grained structure of austenite. Acta Mater. 2015, 84, 1-8. [CrossRef]

23. Godet, S.; Jacques, P.J. Beneficial influence of an intercritically rolled recovered ferritic matrix on the mechanical properties of TRIP-assisted multiphase steels. Mater. Sci. Eng. A 2015, 645, 20-27. [CrossRef] 
24. Xu, Y.B.; Zou, Y.; Hu, Z.P.; Han, D.T.; Chen, S.Q.; Misra, R.D.K. Correlation between deformation behavior and austenite characteristics in a Mn-Al type TRIP steel. Mater. Sci. Eng. A 2017, 698, 126-135. [CrossRef]

25. Cai, Z.H.; Ding, H.; Misra, R.D.K.; Kong, H. Unique serrated flow dependence of critical stress in a hot-rolled Fe-Mn-Al-C steel. Scr. Mater. 2014, 71, 5-8. [CrossRef]

26. Li, Z.C.; Ding, H.; Cai, Z.H. Mechanical properties and austenite stability in hot-rolled 0.2C-1.6/3.2Al-6Mn-Fe TRIP steel. Mater. Sci. Eng. A 2015, 639, 559-566. [CrossRef]

27. Li, Z.C.; Ding, H.; Misra, R.D.K.; Cai, Z.H.; Li, H.X. Microstructural evolution and deformation behavior in the Fe-(6,8.5) Mn-3Al-0.2C TRIP steels. Mater. Sci. Eng. A 2016, 672, 161-169. [CrossRef]

28. Li, Z.C.; Misra, R.D.K.; Cai, Z.H.; Li, H.X.; Ding, H. Mechanical properties and deformation behavior in hot-rolled 0.2C-1.5/3Al-8.5Mn-Fe TRIP steel: The discontinuous TRIP effect. Mater. Sci. Eng. A 2016, 673, 63-72. [CrossRef]

29. Schwab, R.; Ruff, V. On the nature of the yield point phenomenon. Acta Mater. 2013, 61, 1798-1808. [CrossRef]

30. Moor, E.D.; Lacroix, S.; Clarke, A.J.; Penning, J.; Speer, J.G. Effect of Retained Austenite Stabilized via, Quench and Partitioning on the Strain Hardening of Martensitic Steels. Metall. Mater. Trans. A 2008, 39, 2586-2595. [CrossRef]

31. Kim, J.H.; Park, W.S.; Chun, M.S.; Kim, J.J.; Bae, J.H.; Kim, M.H.; Lee, J.M. Effect of pre-straining on low-temperature mechanical behavior of AISI 304L. Mater. Sci. Eng. A 2012, 543, 50-57. [CrossRef]

32. Zou, Y.; Xu, Y.B.; Hu, Z.P.; Gu, X.L.; Peng, F.; Tan, X.D.; Chen, S.Q.; Han, D.T.; Misra, R.D.K.; Wang, G.D. Austenite stability and its effect on the toughness of a high strength ultra-low carbon medium manganese steel plate. Mater. Sci. Eng. A 2016, 675, 153-163. [CrossRef]

33. Lee, S.; De Cooman, B.C. On the selection of the optimal intercritical annealing temperature for medium Mn TRIP steel. Metall. Mater. Trans. A 2013, 44, 5018-5024. [CrossRef]

34. Jimenez-Melero, E.; Dijk, N.H.V.; Zhao, L.; Sietsma, J.; Offerman, S.E.; Wright, J.P.; Zwaag, S.V.D. Martensitic transformation of individual grains in low-alloyed TRIP steels. Scr. Mater. 2007, 56, 421-424. [CrossRef]

35. Wang, J.; Zwaag, S.V.D. Stabilization mechanisms of retained austenite in transformation-induced plasticity steel. Metall. Mater. Trans. A 2001, 32, 1527-1539. [CrossRef]

36. Zhang, S.; Findley, K.O. Quantitative assessment of the effects of microstructure on the stability of retained austenite in TRIP steels. Acta Mater. 2013, 61, 1895-1903. [CrossRef]

37. Hu, H.J.; Xu, G.; Wang, L.; Xue, Z.L.; Zhang, Y.; Liu, G. The effects of $\mathrm{Nb}$ and Mo addition on transformation and properties in low carbon bainitic steels. Mater. Des. 2015, 84, 95-99. [CrossRef]

38. Hu, H.J.; Xu, G.; Zhou, M.X.; Yuan, Q. Effect of Mo Content on Microstructure and Property of Low-Carbon Bainitic Steels. Metals 2016, 6, 173. [CrossRef]

39. Hu, J.; Cao, W.; Wang, C.; Wang, C.Y.; Dong, H.; Li, J. Phase transformation behavior of cold rolled 0.1C-5Mn steel during heating process studied by differential scanning calorimetry. Mater. Sci. Eng. A 2015, 636, 108-116. [CrossRef]

40. Hong, S.C.; Lim, S.H.; Hong, H.S.; Lee, K.J.; Shin, D.H.; Lee, K.S. Effect of Nb on grain growth of ferrite in C-Mn steel during isothermal holding after severe deformation. Mater. Sci. Eng. A 2003, 355, 241-248. [CrossRef]

(c) 2018 by the authors. Licensee MDPI, Basel, Switzerland. This article is an open access article distributed under the terms and conditions of the Creative Commons Attribution (CC BY) license (http://creativecommons.org/licenses/by/4.0/). 